Este artículo tiene como referencia la experiencia de la autora como profesora en Facultades de Artes, a partir de la cual fue siendo formulada una visión de la pedagogia y del arte, aquí presentada bajo la forma de conclusiones previas. Abordando los objetivos del curso de artes, el texto enfoca el comportamiento de los estudiantes delante de lo que les es presentado bajo la forma de actividades de enseñanza y la postura de los profesores en las evaluaciones de los trabajos de esos mismos estudiantes, con el propósito de defender una educación artística basada en valores que potencien conciencias libres, responsables y creativas.

Palabras Clave: Educación artística, pedagogía del arte, conciencia. 


\section{Educación Artistica para el Desarrollo de la Conciencia}

loreto blanco

SALGUEIRO

Este artigo tem como referência a expe-riência da autora como professora em faculdades de Artes, a partir da qual foi sendo formulada uma visão da pedagogia e da arte, aqui apresentada sob a forma de conclusões prévias. Abordando os objetivos do curso de artes, o texto enfoca o comportamento dos estudantes diante do que lhes é apresentado sob a forma de atividades de ensino e a postura dos professores nas avaliações dos trabalhos desses mesmos estudantes, com o propósito de defender uma educação artística baseada em valores que potencializem consciências livres, responsáveis e criativas.

Palavras-chave: Educação artística; pedagogia da arte; consciência. 


\section{Introducción General}

Mi experiencia como profesora universitaria en facultades de Bellas Artes se basa en trece años en los que mi visión de la pedagogía y del arte ha ido evolucionando así como lo he ido haciendo yo misma, desde el ámbito personal y artístico. Cada año me sigo planteando cómo poder mejorar las metodologías y planteamientos que aplico en las clases. Es por esto que lo que expongo a continuación son conclusiones extraidas al día de hoy y que, en un futuro espero, madurarán y se ampliarán según yo misma tenga la capacidad de revisión necesaria para ello.

Estas conclusiones se basan en la asignatura que vengo impartiendo hace unos años y que pertenece al tercer curso de la licenciatura de Bellas Artes de la Universidad de Vigo (incluida en el Departamento de Pintura), es decir, se encuentra ubicada justo en la mitad de los cinco años que son los que en total hay que cursar para licenciarse. La edad media de estos/as alumnos/as es de 20 años.

Según lo que en mi experiencia he podido apreciar, los/las estudiantes en la facultad de Bellas Artes tienden a buscar soluciones fáciles que no les exijan una excesiva profundización, estableciendo muchas veces pautas de trabajo cuyas características se basan en una superficialidad de valores que tienen en cuenta, sobre todo, los estereotipos que se imponen desde el mercado del arte. Valores basados en propuestas efímeras de mercado, donde lo que se lleva es lo que se tiende a realizar o a mimetizar. También puede ocurrir que realicen sus trabajos exclusivamente para el profesor o profesora, es decir, ofreciéndoles lo que sabe les va a gustar, tras realizar una estratégica búsqueda de información previa acerca del tipo de trabajo que realizan, si es que son a su vez un o una artista. 
Pienso que todo profesor/a tiene que hacerse una buena labor de autocrítica y procurar alejar de sus comentarios en clase los juicios excesivamente subjetivos, de gusto personal, procurando en todo momento la objetividad necesaria para propiciar un ambiente donde lo realmente importante es que se potencie lo específico y propio de cada estudiante.

Una adecuada y particular interiorización sensible sólo se logrará si conseguimos, como docentes, alejar inercias y prejuicios. Sólo así el arte podría ayudar a proyectar el potencial humano que reside en cada uno/a de nosotros/as. Hacer comprender al alumna/o que hay una manera de acercarse al arte mucho más rica para el crecimiento y el desarrollo humanos es lo que me interesa hacer desde mi doble papel de artista y de docente.

\section{Objetivos:}

Uno de los objetivos generales del curso se basa en lograr que el/la estudiante encamine su proceso creativo dentro de las particularidades que le son propias. La obra ha de filtrar la forma de percibir y sentir el mundo, indagando y buscando los diferentes grados de apropiación de la realidad que cada uno/a pueda tener. Estos grados de apropiación se basarán en necesidades, deseos, experiencias, vivencias, miedos, etc., todos ellos condicionantes individuales y particulares.

Otro de los objetivos fundamentales a conseguir es que el/la alumno/a se implique consigo mismo/a, mostrando una actitud de compromiso e interés hacia el trabajo que va a realizar. Esta actitud lleva consigo el tener que mostrarse receptivo y abierto a todos los posibles que puedan ir 
surgiendo en su trabajo, o bien sean sugeridos a lo largo del curso, respondiendo con una conducta experimental, es decir, de búsquedas arriesgadas y no de encuentros cómodos y de resultados ya conocidos.

Se hace especial hincapié al comienzo del curso en el carácter experimental del mismo. El objetivo no es que de clase salgan obras perfectamente acabadas para colgar en un lugar expositivo, sino aprender el ejercicio de crear, de experimentar, de poner en cuestión, de interrogarse y aventurarse con sentido y coherencia. Por eso se considerara negativo mostrar una postura inmovilista y cerrada, donde la receptividad a las diferentes propuestas disminuye, provocando una escasa asimilación de conceptos así como un aprendizaje pobre y forzado que no facilita un enriquecimiento en lo personal y humano. Si no existe una actitud abierta y comprometida el programa y los objetivos de la asignatura van a ser difícilmente asimilables y comprendidos.

Otros objetivos más específicos son:

- Sensibilizar al alumnoo/a acerca de los modos de construir una obra artística, rompiendo en este sentido límites o concepciones acotadas acerca de lo que la asignatura puede significar y llegar a abordar. Me refiero con ello a lo que por pintura se puede entender. Aunque este es otro extenso tema que no corresponde extender en este texto, parto de que los límites de la pintura y de los soportes que le pertenecen se han ampliado llegando a confundirse, en ocasiones, las diferentes disciplinas artísticas. En clase se ha de tener total libertad para elegir el soporte que se desee y, sobre todo, el que mejor se adecúe a las necesidades de cada idea y personalidad creativa.

- Otro objetivo es el de adquirir la capacidad de selección y valoración necesarios para abordar el 
acto pictórico desde el ámbito de lo subjetivo. Saber seleccionar modos de acción plástica: formatos, materiales, composiciones, colores, sabiendo lo que se pretende realizar con todo ello. Valorando de qué manera una manipulación u otra del material son las más adecuadas.

- Para ello se ha de poner en marcha otro objetivo, que es el de abordar tanto los modos intuitivos como los racionales y reflexivos. La intuición es la que les hará experimentar, atreverse, aprovechar un ocasional azar, y lo reflexivo será lo que les haga formar criterios de valor y juicio, una necesaria autocrítica, que ayuda a seleccionar y establecer análisis tanto aislados como comparativos.

\section{Metodologia:}

El curso consta de nueve meses y se divide en dos partes de aproximadamente cuatro meses cada una.

El primer cuatrimestre organizo un taller de sensibilización alrededor de la noción de PROCESUALIDAD en relación a la construcción de una obra artística. Es en este cuatrimestre en el que centraré a partir de ahora mi reflexión.

Los temas se dividen de la siguiente manera:

Proceso y Materia:

- Captación, desarrollo y percepción de los sentidos aplicados en la creatividad.

- La superficie pictórica y sus posibilidades.

- La materialidad del soporte.

- Niveles de materialidad e inmaterialidad.

- La materia y el tiempo: la captación del instante.

Proceso y Forma:

- La toma de consciencia en el acto de pintar: con- 
ciencia material,formal, ambiental/contextual, mental y espiritual.

- Proceso y gesto:el proceso y su relación con el movimiento del cuerpo.

- Proceso y equilibrio.

- Proceso y espacio pictórico:el espacio interior a la propia obra y el espacio exterior a la misma.

Proceso y Concepto:

- Proceso e idea: la obra como idea, como proyecto.

- Proceso y subjetividad.

- La actitud del artista como generadora de tendencias.

Este taller de sensibilización se organiza en base a estos contenidos expuestos y se enfoca mediante propuestas muy específicas a realizar en clase y en casa.

La ruptura de inercias y de mecanismos preestablecidos se comienza a aplicar hablándole al alumno/a de la importancia de latoma de consciencia en el proceso creativo. Toma de consciencia entendida como una manera de tomar conocimiento, de darse cuenta. Darse cuenta de uno mismo, de cómo nuestro ser se comporta en la acción plástica en su totalidad, en todo lo que se es, en lo que podamos llegar a saber que somos en el momento actual, en el instante de ejercer nuestra capacidad de crear. En definitiva, les pido que tomen consciencia de lo que es o significa el acto de pintar o, en su sentido más global, el acto de realizar una obra artística, de crear.

En el proceso artístico los tipos de consciencia a adquirir o a tener en cuenta que he distinguido son de cinco naturalezas diferentes: La consciencia matérica, la consciencia formal, la consciencia ambiental o contextual, la consciencia mental y la consciencia espiritual. Voy introduciendo al estudiante en estos cinco grados mediante una 
propuesta práctica acompañada de unos textos seleccionados, con el fin de que éstos les sirvan de apoyatura reflexiva paralela al trabajo de taller. La doble intención que pretendo con esta metodología es estimular un proceso creativo en donde práctica y reflexión caminen conjuntamente, de manera porosa, enriqueciéndose de forma mutua y entendiendo que estos ámbitos de trabajo han de estar unidos en una perfecta complicidad para que el proceso funcione simultáneamente desde niveles intuitivos y racionales.

\section{Contenido:}

Abordaremos a continuación los cinco grados de consciencia más arriba expuestos, eje vertebral de la docencia del primer cuatrimestre.

La consciencia material: Nos remite al estudio y sensibilización de las características materiales y físicas de lo que seleccionamos en el proceso creativo, bien referidas a las características físicas propias del punto de partida o idea con la que seva a trabajar, bien con la de los materiales y soportes que utilizaremos para transmitirla.

Es la parte del proceso donde se ha de elegir el material idóneo para la plasmación plástica deseada, así como el nivel de materialidad o inmaterialidad buscados: cantidad de materia, cualidades de la materia (levedad, pesadez, fluidez...), elección de la calidad textural del soporte (grano, porosidad, etc...) así como la idoneidad de su tamaño para la mejor adecuación de lo que se pretende transmitir.

La Consciencia Formal: nos remite a la importancia del gesto en el proceso de elaboración de la obra, gesto como constructor de formas que equilibran y construyen un espacio sobre la superficie 
de un soporte. El gesto y también las relaciones que el cuerpo establece con el soporte desde el movimiento que genera.

El cuerpo se convierte en una herramienta fundamental de trabajo sin la cual la obra no puede llegar a materializarse (gestualizarse). La evidencia de este conocimiento es lo que hace que nos olvidemos de él y casi siempre terminemos moviéndonos de manera automática, con gestos aprendidos o mecánicos, e incluso a veces en una especie de "fuera de sí". Es importante darse cuenta de la relación que establecemos con él a lo largo de todo el proceso.

Nuestro cuerpo físico constituye en el proceso creativo una herramienta sensible, amplia y poderosa, y es importante saberla manejar, o bien dejarmos que nos maneje pero a conciencia, como recurso metodológico estratégico.

"El cuerpo...No es objeto ni sujeto, es la exteriorización progresiva y continua de sí mismo, una presencia de la que tenemos completa certidumbre pero que olvidamos siempre. Es la alienación básica porque nunca es el mismo, está haciéndose diferente para existir. Cuando nos movemos o desplazamos, no tenemos presente nuestro cuerpo. Así, aunque es material y lo podemos tocar, cuando actúa nos resulta invisible."

Es nuestro cuerpo el que se mueve delante o alrededor del soporte plástico y lo hará de una manera u otra dependiendo de la exteriorización o gesticulación que queramos hacer del mismo. Hemos de darnos cuenta de cual es la relación que nuestro cuerpo establece con la obra durante el proceso de creación. Así podremos observar la fluidez o rigidez que adopta, el ritmo y los movimientos que ejecutamos. De ahí podremos darnos cuenta de cómo estamos, es decir, si nos encontramos nerviosos, seguros, inseguros, serenos, si los movimientos son lentos, rápidos, bruscos, ruti- 
narios, mecánicos, tímidos, etc. Y a partir de esa toma de conciencia preguntarnos si realmente el carácter de nuestros movimientos se corresponde con lo que buscamos expresar, con lo que sentimos que nos identificamos más profundamente, con lo que, en definitiva, buscamos ser.

Este proceso pone en camino de darse cuenta de la fase vital en la que uno/a se encuentra, y sobre todo, en el camino de tomar nuevas determinaciones gestuales y corporales para dirigirse hacia lo que se desea ser y, probablemente, ya nos contenga, a la espera de dejarlo surgir.

Tras la acción plástica se puede observar si su comportamiento durante el proceso y el resultado obtenido han sido o no los idóneos para lograr la expresión deseada. Es necesario para lograr este objetivo, ejercer una capacidad de autocrítica sincera donde cada cual es quien mejor conoce hasta donde llegó su implicación, así como el camino que le queda para alcanzar un resultado satisfactorio, donde las intenciones y los resultados estén perfectamente fusionados.

La consciencia gestual nos hará, a su vez, tomar mayor conocimiento de áreas específicas de nuestro cuerpo: movimientos de muñeca, dedos, manos, codos, brazos, ojos, piernas, tronco.. . Al darnos cuenta de cómo se mueven las diferentes partes durante la acción pictórica pueden ir surgiendo nuevos gestos, ritmos y huellas motivados por ese despertar de la sensibilización corporal. Estos nuevos gestos corporales originarán, a su vez, nuevos gestos pictóricos, y éstos aportarán diferentes posibilidades expresivas a la imagen que generemos. Todo ello nos hará tomar una mayor conciencia de las posibilidades que se abren en la utilización del cuerpo como herramienta del proceso creativo.

Esta mirada atenta en la que nos damos cuenta de detalles que nos pasaban hasta entonces inad- 
vertidos posibilita la ampliación del vocabulario plástico utilizado hasta ese momento, enriqueciéndolo tanto a niveles formales como sensibles.

Los aspectos a valorar en esta toma de consciencia son, en definitiva, los siguientes:

- el gesto y los ritmos que se establecen en concordancia a una intención. Para ello se han de valorar, a su vez, sus cualidades. Tipo de gesto que crean formas cerradas, formas abiertas, formas expansivas, informes, etc...,

- la existencia de fluidez o rigidez corporal,

- el equilibrio compositivo que generan los elementos distribuidos por el soporte. El estudio de una composición adecuada.

La Consciencia Ambiental/Contextual: tomamos como referencia la relación con el espacio que envuelve a la forma, idea o punto de referencia inicial del proceso creativo. Este espacio se estudia desde dos aspectos: el espacio que se genera desde la propia obra y el espacio contextual, es decir, entendido desde una realidad histórica y social en donde la obra se incluye espacio/temporalmente.

En cuanto al primero de los aspectos mencionados tendríamos una valoración del espacio en donde nos preguntaríamos por sus cualidades y su necesidad de ser. Es decir, ¿Cual es el espacio que se busca o desea transmitir en concordancia con la idea o punto de partida buscada? Para ello podemos plantearnos cuales serían las posibles cualidades que tendría ese espacio: densidad, fluidez, amplitud, vacuidad, acotación, sublimidad, inmensidad..., y un largo etcétera, puesto que podríamos añadir una infinidad de adjetivos calificativos que diversificarían las intenciones espaciales de la obra a realizar.

También abordaríamos en este apartado otra problemática espacial que tendría en cuenta el tipo de espacio generado en el interior de la obra. 
Así tenemos la posibilidad de utilizar diferentes espacios:

- un espacio ilusionista, en donde se busca una ilusión de realidad (Renacimiento), dominada por la función mimética, por la representación que busca una copia fiel de las apariencias ópticas del mundo visible.

- un espacio fragmentado, donde la composición se fragmenta en diferentes planos de lectura, bien utilizando diferentes unidades soporte o bien sucediendo sobre la misma unidad (superposición, disgregación, discontinuidad...)

- un espacio de literalidad, donde se establecen relaciones desde la propia piel del soporte o pintura, remarcándose con ello las características bidimensionales y planas de la obra (abstracción).

Así como estudiamos el comportamiento del espacio generado desde el interior de la obra podemos comenzar también a observar cómo ésta genera un sistema de relaciones espaciales en función del lugar en el que es colocada. Se ha de valorar la importancia del lugar que ocupa la obra en el espacio destinado para su visualización. Para ello ofrecemos al alumno/a una serie de posibilidades sobre las que se ha de cuestionar la idoneidad respecto a la lectura espacial buscada. Estas posibilidades son: Colocar, instalar, contextualizar y ambientar. Todas ellas planteadas con límites porosos no excluyentes en donde se puede partir de uno de los conceptos y llegar al otro por su propio desarrollo. Se puede, por ejemplo, partir de una simple noción de colocación de una serie de cuadros en un espacio expositivo y puede surgir, a partir de ello, un ambiente envolvente para el espectador, o bien una zona de contextualización importante debido a una mayor densificación zonal que remarca la visión compositivamente puntual en el espacio. 
En cuanto al segundo ámbito de procedencia espacial al que nos referimos más arriba, en referencia al contexto espacio temporal, planteamos la importancia de tomar conocimiento y no obviar los intereses, intenciones y deseos que plantea la época histórica en la que nos ha tocado vivir. Conocer la procedencia y los devenires por los que el arte ha evolucionado y realizado sus cambios en relación a las revoluciones o cuestionamientos que a su vez se plantearon las distintas sociedades y culturas a lo largo del tiempo es fundamental. El arte avanza en la medida en que el hombre es capaz de transformarse y transformar la sociedad y la cultura en la que vive. Existe, por tanto, una evidente responsabilidad con la época en la que estamos implicados y, en consecuencia, el espacio contextual de la obra lo ha de tener en cuenta para ser hija de su tiempo y realizar una posible aportación hacia el futuro.

La Consciencia Mental o Conceptual: Tras hacer un recorrido por las partes del proceso creativo propiamente externas al objeto de producción, es decir, en las que nos ocupamos prioritariamente de establecer parámetros de equilibrio y formalización encaminados a una elaboración objetual eficaz y coherente, en esta parte empezamos a valorar aspectos particularmente dirigidos a nuestro interior, a los deseos e intenciones que establecen relaciones mentales internas, con el sentido de permitir aflorar lugares de nuestro inconsciente, tanto personal como colectivo. Lugares que habitan en nuestro interior y nos producen extrañamientos e interrogantes, poniendo en marcha reflexiones y renovaciones vitales integradas en nuestra cotidianeidad, en nuestra experiencia personal. Interactuamos en un mundo donde la realidad no es tan sólo aquello que se encuentra desplegado ante nosotros, es decir, un mundo donde sólo nos afecta la realidad que vemos y tocamos. Habitamos tam- 
bién en un mundo en el que coexiste además otro tipo de realidad plegada, es decir, una realidad no visible para nuestros sentidos o instrumentos de percepción, pero que sentimos y experimentamos igualmente, afectando y actuando en nuestras vidas de forma permanente.

Hacernos al menos conscientes de la coexistencia de estas realidades es uno de los objetivos a cumplir en este cuarto apartado, encaminado a recorrer los grados de consciencia del proceso creativo. Para ello se invita al alumno/a a trabajar a partir de una psicología o carácter que ha de seleccionar teniendo en cuenta el amplio campo de posibilidades que ofrece el ser humano, desde su manera de relacionarse con el mundo. Los puntos de partida pueden surgir a partir de considerar centrarse en temáticas específicas, como por ejemplo los miedos, los deseos, los límites que cada uno/a establece con su entorno vital (familiar, profesional, social...). El trabajar a partir de un aspecto de la psicología o carácter humanos para construir una obra artística que transmita o plantee una relación con el espectador desde estos parámetros psicológicos conlleva plantearse, como creador y como ser humano, con qué aspectos se siente atraído o cercano para trabajar, así como a realizarse preguntas y buscar imágenes, formatos, materiales, intenciones, etc.

Comienza a existir en esta parte del proceso la consciencia de que la obra se dirige a un posible espectador y que ello implica para el hacedor de objetos u obras, "el creador", una responsabilidad específica, que es la de ofrecer a la sociedad un producto con un potencial expresivo y comunicador determinados, es decir, un producto que potencialmente plantea cuestiones de alguna índole, produce reacciones específicas, afecta de alguna manera al lado sensible, anímico, intelectual del observador que se sitúa en disposición receptiva ante la 
obra. Normalmente el estudiante no se sitúa en el lugar del espectador, ni se plantea la función social que la obra que realiza pueda abordar. Se trabaja un poco inconscientemente en este aspecto. Creo que educar en la consciencia de que la obra lleva implícita una ética que se transmite a todo aquel que la observa es fundamental, puesto que ayuda al artista o futuro artista a darse cuenta de la responsabilidad que implica el mostrarla en un lugar público y con ello interrogarse acerca de qué es lo que quiere ofrecer, para qué y por qué.

Es por tanto uno de los aspectos a tener en cuenta la actitud con la que todo artista se posiciona libremente frente a la obra y su función social. Para enfocar una primera elección o acercamiento es conveniente ofrecer una orientación acerca de algunas posibles actitudes existentes. A modo general y quizás estereotipada, tras realizar una revisión del comportamiento y actitudes artísticos en el siglo XX podemos destacar las siguientes particularidades:

- El artista comercial: cuyo interés fundamental se centra en conseguir una obra que guste estéticamente y cuyo fin es que tenga una fácil colocación en el mercado. Para ello estará al tanto de las modas del momento y de lo que se vende. Ganar un dinero fácil es su objetivo y no se plantea que el arte pueda cumplir otra función que la meramente decorativa y lucrativa.

- El artista provocador/subversivo: Distinguiría aquí dos apreciaciones opuestas, la primera la conformaría el artista que quiere despertar algún tipo de sensación aletargada o inhibida en un preciso contexto social o dirigida a algún tipo de estamento social. Podrían entran a formar parte de este elenco de artistas todos aquellos que plantean algún tipo de denuncia, sea política, ecológica, social, etc. Artistas que quieren romper con sus obras inercias o modos de comportamiento hu- 
manos, o quizás hacernos ver de qué manera nos comportamos frente a algunos hechos cotidianos de la vida. Para ello utilizan imágenes de cierta fuerza o contundencia narrativa que no dejen margen al equívoco y cuyo mensaje suele ser directo y efectivo.

La segunda apreciación que destacaría en este mismo apartado sería la de los artistas que, efectivamente, son provocadores pero, a diferencia de los anteriores, detrás de dicha provocación existe poco más que un afán de llamar la atención o sobresalir de forma rápida y efectista. Tras la provocación de lo inmediato no existe ningún matiz que el espectador deba de recibir o a través del cual se le haga algún tipo de planteamiento o cuestión. Como quien va en una montaña rusa el espectador disfruta, o no, de la obra, como un juego de consumo rápido, y tras digerirla pasa a otra cosa encontrándose igual, o a veces peor, de cómo se encontraba en un inicio.

- El artista trascendente: Situaría aquí a aquellos artistas que consideran al arte como parte de su vida y que se plantean el camino artístico como un modo de autoconocimiento en el cual la parte sensible, intuitiva, racional..., entra a formar parte de múltiples formas y matices. Este artista se toma su trabajo como una forma de avanzar a la vez en su vida, siendo a través de su desarrollo que van comprendiendo el mundo, contestando y planteando interrogantes, tomando apreciaciones nuevas de cómo verlo, entenderlo o moverse en él. Esta sería la actitud que plantearía y propondría al espectador. La obra como cuestionadora de aspectos de su interior, de su visión del mundo, de las relaciones que es capaz de establecer consigo mismo respecto a su exterior.

- El artista irónico (la banalización): aquí se encontraría el artista que conoce los modos de comportamiento del arte y los utiliza estratégicamen- 
te para ironizar sobre sus supuestos o para ridiculizar aspectos desde estos mismos postulados. La ironía, la burla, la ridicularización, el mostrar vacuidades o temas de forma irrisoria, burlesca, morbosa incluso, para crear en el espectador una risa fácil, "sonrisas despectivas", incredulidad, morbo o comentarios jocosos.

Estos cuatro estereotipos, quizá exageradamente presentados, nos sirven de referencia a modo de incitación provocadora al estudiante, que ha de inclinarse hacia un posicionamiento inicial donde quizá se sitúe procediendo más por eliminación que no por segura convicción en alguno de ellos. Hay que entender que estas actitudes prototipos propuestas no siempre van enunciadas en la realidad tan radicalmente, sino que se matizan y entrelazan entre ellas, creando artistas de muy diferentes y mezclados matices posturales.

Es importante a este nivel tener referencias teóricas que defiendan las diferentes posturas, pudiendo crear debates confrontando los argumentos que plantean las diferentes actitudes. Así podemos confrontar, por ejemplo, textos del libro "El arte en la posmodernidad.Todo vale" y su capítulo El que no sale no vale. El papel del artista en la sociedad contemporánea, con otros del libro de Andrei Tarkovski "Esculpir en el tiempo" y su capítulo El ansia de lo ideal.

La Consciencia Espiritual: Como un último aspecto en este recorrido hacia la toma de consciencia en el acto creativo planteamos esta última toma de consciencia. En ella nos enfocamos en el ser humano que existe tras todo artista o creador. Planteamos el ser espiritual como un todo al que se tiende, a cuyo encuentro se dirige uno en la vida, completándose y descubriendo lo que habita en el interior de cada uno/a de nosotros/as. El ser desde lo que ya conocemos como presencia y el ser que desde la ausencia también presentimos o bus- 
camos. Esto se liga con lo que más arriba enunciaba como el mundo desplegado y el mundo o realidad plegada, oculta. La realidad desplegada es la que nos liga al mundo visible y perceptible desde los esquemas aprendidos socialmente por todos y gracias a los cuales habitamos con "orden" en una misma comprensión de la realidad común y el mundo. La realidad plegada es la que se nos pliega y oculta habiendo de abordarla desde nuestro interior, único y específicamente original, para descubrir y hacernos conscientes de las otras realidades que conviven en nosotros haciéndonos conscientes de nuevos potenciales, matices, conocimientos.

Consciencia e inconsciencia se encuentran ligados e indisolublemente unidos, puesto que penetrar en nuestra inconsciencia con una actitud de apertura a una realidad interior, nos hace asequibles nuevos conocimientos que se integran a nuestro ser constituyéndonos en el potencial global que nos habita. Construyendo de este modo nuestro ser espiritual, nuestro ser completo en todas las unidades/realidades que le pertenecen. El arte puede convertirse en un camino de acceso a esas realidades inconscientes, puesto que en el proceso creativo se libera nuestro lado intuitivo y pueden aflorar relaciones que hasta entonces permanecían inhibidas. Puede así el arte convertirse en un modo de adquirir conciencia, de hacernos conscientes, de comprendernos y hacernos como seres humanos completos, afrontando el camino del arte como un camino que nos conduce hacia la unidad del ser, aunando presencia y ausencia, consciencia e inconsciencia, exterior e interior. 


\section{Conclusion:}

La educación artística puede orientarse hacia un objetivo fundamental no centrándose en exclusiva hacia el exterior sino apostando por una orientación enfocada al interior del ser humano. Buscar que exterior e interior vayan unidos configurando un nuevo modelo educativo. Para ello aspectos más técnicos, formalistas, estéticos, han de ser entendidos desde un ámbito mucho más amplio, dándoles un sentido coherente y completo, para que forma y fin tengan una unidad/realidad ética y estética, que pueda conducir al ser (hacedor y observador) hacia un camino de formación y construcción interior completa y global.

Proponemos y defendemos, en definitiva, una educación basada en valores, que busca potenciar conciencias libres, responsables, creativas. Sabemos que el pragmatismo imperante no deja mucho margen de acción en este sentido. Lo práctico, la eficacia, la rentabilidad rápida y efectiva son los valores que nos empujan y envían continuamente desde el exterior, anulando las respuestas creativas, diferentes, que no propugnan soluciones rápidas, sino lentas miradas de contemplación y cambios de concepciones acerca de lo que es más importante o válido para la sociedad. Como en todos los cambios se necesita tiempo para hacer surgir con plenitud realidades nuevas. Las nuevas concepciones siempre son, inicialmente, apuestas en las que se cree con fuerza y en las que hay que invertir grancantidad de energía. Esta energía proviene necesariamente del entusiasmo y del deseo de vivir en un mundo mejor, donde el hombre aprenda a habitar, dialogar y conocerse más a sí mismo.

La ciencia y la tecnología han evolucionado de forma tremenda y rápida, continúan haciéndolo, mientras que el interior del ser humano no ha ex- 
perimentado la misma evolución. Ciencia y filosofía (pensamiento, conocimiento interior humano) se han bifurcado de tal manera que la una va independiente de la otra. La primera ha evolucionado tremendamente frente al estancamiento o lento crecimiento de la segunda. Esto ha creado un gran desequilibrio en donde el siglo XXI, y la educación artística en concreto, tiene un importante y gran papel que ejercer cara a establecer un futuro donde vuelvan a equilibrarse y en el que se establezca un nuevo orden.

\section{Cangas del Morrazo. España}

25 de enero del 2003

\section{Referências Bibliográficas}

GURMÉNDEZ, Carlos. Teoria de los sentimientos. Madrid: FCE, 1984.

Loreto Blanco Salgueiro é professora do Departamento de Pintura da Facultad de Bellas Artes, Universidad de Vigo, España. 